\title{
Missed opportunity to screen and diagnose PTSD and depression among deploying shipboard US military personnel
}

\author{
Judith Harbertson, Braden R. Hale, Nelson L. Michael and Paul T. Scott
}

\section{Background}

Depression and post-traumatic stress disorder (PTSD) are significant risks for suicide and other adverse events among US military personnel, but prevalence data among ship-assigned personnel at the onset of deployment are unknown.

\section{Aims}

To determine the prevalence of shipboard personnel who screen positive for PTSD and/or major depressive disorder (MDD) at the onset of deployment, and also those who reported these diagnoses made by a physician or healthcare professional in the year prior to deployment.

\section{Method}

Active-duty ship-assigned personnel $(N=2078)$ completed anonymous assessments at the beginning of deployment. Depression was measured using the Center for Epidemiologic Studies Depression Scale (CES-D; score of $\geq 22$ ), and PTSD was assessed using the PTSD Checklist-Civilian Version (PCL-C; both score and symptom criteria were used).

\section{Results}

In total, $7.3 \%$ ( $n=151$ of 2076) screened positive for PTSD and $22 \%$ ( $n=461$ of 2078) for MDD at deployment onset. Only $6 \%$ and $15 \%$ of those who screened positive for PTSD or MDD, respectively, had been diagnosed by a healthcare professional in the past year.

\section{Conclusions}

Missed opportunities for mental healthcare among screenpositive shipboard personnel reduce the benefits associated with early identification and linkage to care. Improved methods of mental health screening that promote early recognition and referral to care may mitigate psychiatric events in theatre.

\section{Declaration of interest}

This work was performed as part of the official duties of the authors as military service members or employees of the US Government.

\section{Copyright and usage}

This work was prepared by military service members or employees of the US Government as part of their official duties. As such, copyright protection is not available for this work (Title 17, USC, §105).
Depression and posttraumatic stress disorder (PTSD) are significant risks for suicide and other adverse outcomes among US military personnel. ${ }^{1}$ While shipboard personnel receive a standard medical evaluation prior to deployment, unlike their land-based counterparts, they do not complete the Pre-Deployment Health Assessment (Pre-DHA). The Pre-DHA includes standardized screening tools for PTSD and depression and is difficult to administer in the shipboard environment. The beginning of a shipboard deployment is associated with multiple significant stressors, yet little is known about depression and PTSD prevalence during this period when existing conditions may be worsened. We report on the prevalence of shipboard personnel who screened positive for PTSD and/or depression at the onset of deployment, and those who reported a diagnosis by a physician or other healthcare professional (HCP) in the year prior to that deployment. A significant number of personnel were screen-positive for PTSD or depression, yet few had received an $\mathrm{HCP}$-diagnosis for these concerns.

\section{Method}

US Navy and Marine Corps active-duty personnel completed a selfreported anonymous pre-deployment paper survey within approximately 2 weeks of deployment (described in detail elsewhere). ${ }^{2}$ Briefly, data were collected from 11 ships as part of a longitudinal study assessing risks for sexually transmitted infections. Convenience sampling was used and coordinated through all available department heads based on personnel availability to represent a broad spectrum of shipboard personnel. PTSD and depression were assessed using the PTSD Checklist-Civilian Version (PCL-C) ${ }^{3}$ and Center for Epidemiologic Studies Depression Scale (CES-D), respectively. ${ }^{4}$

Screening positive for PTSD was defined as a PCL-C score of $\geq 50$ and endorsement of a moderate level of $\geq 1$ intrusion symptoms, $\geq 3$ avoidance symptoms, and $\geq 2$ hyperarousal symptoms,${ }^{5-8}$ consistent with DSM-IV criteria. Being at risk for major depressive disorder (MDD) was defined as a CES-D score of $\geq 22$. Participants who reported a diagnosis of depression and/or PTSD by a doctor or HCP in the past 12 months were considered to have had a clinical diagnosis (HCP-diagnosis).

Data were analysed using SAS software version 9.3 (SAS Institute, Inc., Cary, NC). Participants with $\leq 1$ missing questions on the assessment and PTSD and/or depression diagnosis survey question(s) were included in the denominator of the mental health diagnosis analysis. Pearson's chi-squared or Fisher's exact tests were used to determine statistical significance of categorical variables. All independent variables were included in the multivariable regression model. No collinearity was observed using a tolerance $\leq 0.10$. All $P$-values were based on two-tailed tests of significance, defined as $P \leq 0.05$.

\section{Results}

A total of 2543 participants met the inclusion criteria. ${ }^{2}$ Those who did not complete the PTSD or depression assessment were excluded; final sample sizes were 2076 and 2078 for PTSD and depression, respectively. 


\begin{tabular}{|c|c|c|c|c|c|c|}
\hline \multirow[b]{3}{*}{ Characteristics } & \multicolumn{3}{|c|}{ PTSD } & \multicolumn{3}{|c|}{ Depression } \\
\hline & Total & \multicolumn{2}{|l|}{ Screen positive } & \multirow{2}{*}{$\begin{array}{l}\text { Total } \\
n(\%)\end{array}$} & \multicolumn{2}{|l|}{ MDD } \\
\hline & $n(\%)$ & $n(\%)$ & $\mathrm{AOR}^{\mathrm{C}}$ & & $n(\%)$ & $\mathrm{AOR}^{\mathrm{d}}$ \\
\hline Total & $2076(100.0)$ & $151(7.3)$ & & $2078(100.0)$ & $461(22.2)$ & \\
\hline HCP-diagnosed ${ }^{e}, n / N(\%)$ & & 8/141 (5.7) & & & /436 (14.7) & \\
\hline \multicolumn{7}{|l|}{ Gender } \\
\hline Male & $1615(77.8)$ & $107(6.6)^{\star}$ & 1.0 & $1623(78.1)$ & $313(19.3)^{\star *}$ & 1.0 \\
\hline Female & $461(22.2)$ & $44(9.5)$ & $1.1(0.8-1.7)$ & 455 (21.9) & $148(32.5)$ & $1.6(1.3-2.1)$ \\
\hline \multicolumn{7}{|l|}{ Age, years } \\
\hline 17-19 & $99(4.8)$ & $10(10.1)$ & $2.7(0.7-10.1)$ & $101(4.9)$ & $29(28.7) * *$ & $2.2(1.0-5.2)$ \\
\hline $20-24$ & $938(45.2)$ & $74(7.9)$ & $1.7(0.6-5.1)$ & $938(45.1)$ & $229(24.4)$ & $1.5(0.8-3.0)$ \\
\hline $25-29$ & $488(23.5)$ & $38(7.8)$ & $1.5(0.5-4.3)$ & $494(23.8)$ & $111(22.5)$ & $1.4(0.7-2.7)$ \\
\hline $30-39$ & $442(21.3)$ & $24(5.4)$ & $0.9(0.3-2.7)$ & $438(21.1)$ & 78 (17.8) & $1.2(0.6-2.2)$ \\
\hline$\geq 40$ & 109 (5.3) & $5(4.6)$ & 1.0 & $107(5.2)$ & $14(13.1)$ & 1.0 \\
\hline \multicolumn{7}{|l|}{ Service branch } \\
\hline Navy & $1766(85.5)$ & $140(7.9)^{\star *}$ & $2.8(1.4-5.7)$ & $1766(85.4)$ & $416(23.6)^{* *}$ & $1.9(1.3-2.8)$ \\
\hline Marine Corps & $300(14.5)$ & $11(3.7)$ & 1.0 & $301(14.6)$ & $44(14.6)$ & 1.0 \\
\hline \multicolumn{7}{|l|}{ Military rank } \\
\hline E1-E3 & $695(33.7)$ & $60(8.6)^{\star}$ & $2.1(0.9-4.9)$ & $698(33.8)$ & $176(25.2)^{\star *}$ & $1.5(0.9-2.4)$ \\
\hline E4-E6 & $1114(54.0)$ & $81(7.3)$ & $1.6(0.7-3.6)$ & $1115(53.9)$ & $248(22.2)$ & $1.4(0.9-2.2)$ \\
\hline E7-E9, W1-W5, 01-09 & $256(12.4)$ & $10(3.9)$ & 1.0 & 255 (12.3) & 37 (14.5) & 1.0 \\
\hline \multicolumn{7}{|l|}{ Number of deployments ${ }^{f}$} \\
\hline 0 & $454(22.6)$ & $30(6.6)$ & $0.6(0.4-1.0)$ & $454(22.6)$ & $118(26.0)^{*}$ & $1.1(0.8-1.5)$ \\
\hline 1 & $662(32.9)$ & $51(7.7)$ & $0.8(0.5-1.2)$ & $669(33.3)$ & $162(24.2)$ & $1.0(0.8-1.4)$ \\
\hline$\geq 2$ & $894(44.5)$ & $64(7.2)$ & 1.0 & $889(44.2)$ & $170(19.1)$ & 1.0 \\
\hline \multicolumn{7}{|l|}{ Race/ethnicity } \\
\hline Non-Hispanic White & $1102(53.9)$ & $56(5.1)^{\star *}$ & 1.0 & $1106(54.0)$ & $211(19.1)$ & 1.0 \\
\hline Non-Hispanic Black & $253(12.4)$ & $26(10.3)$ & $2.0(1.2-3.3)$ & $253(12.4)$ & 67 (26.5) & $1.3(0.9-1.8)$ \\
\hline Hispanic/Latino & $303(14.8)$ & $30(9.9)$ & $1.7(1.1-2.9)$ & $300(14.7)$ & $78(26.0)$ & $1.4(1.0-1.9)$ \\
\hline$\geq 2$ race/ethnicities & $153(7.5)$ & $23(15.0)$ & $3.0(1.7-5.1)$ & $154(7.5)$ & $56(36.4)$ & $2.1(1.4-3.0)$ \\
\hline Other & $232(11.4)$ & $15(6.5)$ & $1.2(0.7-2.3)$ & $235(11.5)$ & $44(18.7)$ & $1.0(0.7-1.4)$ \\
\hline \multicolumn{7}{|l|}{ Marital status } \\
\hline $\begin{array}{l}\text { Single, never married, } \\
\text { uncommitted }\end{array}$ & $622(30.0)$ & $36(5.8)^{*}$ & $0.7(0.5-1.2)$ & $617(29.7)$ & $136(22.0)^{*}$ & $0.9(0.7-1.3)$ \\
\hline $\begin{array}{l}\text { Single, in committed } \\
\text { relationship }\end{array}$ & $361(17.4)$ & $34(9.4)$ & $1.2(0.7-2.0)$ & $366(17.6)$ & 99 (27.1) & $1.2(0.8-1.6)$ \\
\hline $\begin{array}{l}\text { Single, living with } \\
\text { partner }\end{array}$ & $98(4.7)$ & $6(6.1)$ & $1.0(0.4-2.4)$ & $98(4.7)$ & $24(24.5)$ & $1.2(0.7-2.1)$ \\
\hline Married & $850(41.0)$ & $58(6.8)$ & 1.0 & $856(41.2)$ & $166(19.4)$ & 1.0 \\
\hline $\begin{array}{l}\text { Divorced, separated, } \\
\text { or widowed }\end{array}$ & $143(6.9)$ & $17(11.9)$ & $1.8(1.0-3.3)$ & $139(6.7)$ & $35(25.2)$ & $1.3(0.8-2.0)$ \\
\hline \multicolumn{7}{|c|}{$\begin{array}{l}\text { PTSD, posttraumatic stress disorder, MDD, major depressive disorder. } \\
\text { a. Based on a PTSD Checklist-Civilian Version score of } \geq 50 \text { and symptom criteria, past month. } \\
\text { b. Based on a Center for Epidemiologic Studies Depression Scale score of } \geq 22 \text { (MDD), past week. } \\
\text { c. Multivariable regression modeled probability of screening positive for PTSD, } n=1981 \text {. } \\
\text { d. Multivariable regression modeled probability of screening positive for MDD, } n=1986 \text {. } \\
\text { e. Proportion of individuals who reported a diagnosis of depression and/or PTSD by a doctor or healthcare professional (HCP) in the past } 12 \text { months among those at risk for MDD and/ } \\
\text { or PTSD. } \\
\text { f. Number of official deployments completed. } \\
{ }^{*} P \leq 0.05 ;{ }^{* *} P \leq 0.01 ; \text { for adjusted odds ratios shown in bold, for PTSD model overall } P \text {-values: service branch, } 0.0037 \text {; race/ethnicity, } 0.0006 \text {; for MDD model overall P-values are: gender, } \\
0.0003 \text {; service branch, } 0.0008 ; \text { race/ethnicity, } 0.0010 \text {. }\end{array}$} \\
\hline
\end{tabular}

In total, 7.3\% ( $n=151 / 2076)$ screened positive for PTSD, and $22.2 \%(n=461 / 2078)$ for MDD. Among those who screened positive for PTSD, $87.7 \%(n=128 / 146)$ were at risk for MDD.

Not all participants who completed the PTSD and/or depression assessment reported whether a physician had diagnosed them with PTSD and/or depression (HCP-diagnosis), so the denominator differs. Overall, only $5.7 \%(n=8 / 141)$ of those who screened positive for PTSD and $14.7 \%(n=64 / 436)$ of those who are at risk for MDD had an HCP-diagnosis.

Among personnel at risk for depression, a significantly larger proportion of women with MDD $(20.3 \%, n=29 / 143)$ had an HCPdiagnosis than men $(12 \%, n=35 / 293, P=0.02)$. No statistically significant differences by gender were observed for PTSD diagnosis among those who screened positive for PTSD (women: 7\%, $n=3 / 43$, men: $5.1 \%, n=5 / 98)$. There were few individuals who screened negative for MDD or PTSD (2\%, $n=32 / 1571$ and $1 \%, n=21 / 1863$, respectively) but reported an $\mathrm{HCP}$-diagnosis.

After adjusting for all demographics, the odds of screening positive for PTSD were significantly higher among those reporting Navy service branch than Marine Corps and nonHispanic Black, Hispanic/Latino or two or more race/ethnicities compared with non-Hispanic White race/ethnicity (see Table 1). The odds of being at risk for MDD were significantly higher among females, Navy service branch, and those 
reporting two or more race/ethnicities after adjusting for all other demographics.

\section{Discussion}

Among shipboard US Navy and Marine Corps personnel who screened positive for PTSD and/or depression at deployment onset (predominantly Navy, female, non-White race/ethnicities, Table 1), very few self-reported PTSD and/or depression diagnosis in the past year, revealing a potentially large unmet need for mental healthcare. Missed opportunities for mental healthcare among screen-positive personnel, previously reported within the US military, ${ }^{5}$ reduces the benefits associated with early identification and linkage to care. ${ }^{1}$ Evidence shows improved methods of mental health screening that focus on deployment disqualifying mental health criteria prior to land-based deployment linked to in-theatre care substantially reduces the number of in-theatre personnel seeking clinical care for psychiatric disorders or suicidal ideation, and operational restrictions or evacuation for mental health conditions. ${ }^{9}$ Few soldiers deploying to Iraq $(7.7 \%$, $n=819 / 10678)$ required further mental health evaluation and only $6 \%(n=48)$ of those were not deployable. Integrated screening and monitoring among shipboard personnel may present similar benefits, particularly if the pre-deployment screening period allowed sufficient time for proper evaluation and implementation of measures to ensure sustained access to appropriate medication and/or other treatment before an extended shipboard deployment.

Individuals who have elevated PTSD and depression scores, or comorbid PTSD/depression ${ }^{10}$ on the Pre-DHA, could be targeted for specialised mental health evaluations; personnel with modestly elevated depression and PTSD scores could receive evidence-based non-medical interventions shown to reduce symptoms ${ }^{11-15}$ although additional research is needed to confirm benefits to the shipboard population. Females, those reporting Navy service branch and non-Hispanic Black, Hispanic/Latino and two or more race/ethnicities were significantly more likely to screen positive for either PTSD or depression, and additional studies could validate whether these individuals are at highest risk using clinical diagnostic interviews to inform interventions that target individuals at highest risk.

The current study PTSD and MDD prevalence is slightly higher ${ }^{6,16,17}$ or lower ${ }^{17,18}$ compared with other military populations, but study design differences (e.g. scoring criteria and surveydeployment temporal relationship) make comparisons difficult. Adjusted analyses showed that those reporting Navy service branch had higher odds of PTSD and depression than Marine Corps. Previous data among the US military show higher mental health disorder prevalence among Marine Corps than Navy, ${ }^{19,20}$ but these studies reported unadjusted data, used different assessment tools, and were not timed around a deployment. It is possible that Marine Corps personnel assigned to a shipboard deployment may differ from land-assigned Marine Corps, but this would need to be examined further.

There are several possible explanations for the observed high depression and PTSD screen-positive prevalence in the current study, including limitations inherent to screening tools applied to a general population, such as increased false-positivity; increased reporting on anonymous surveys; and the possibility that mental health symptoms increase immediately prior to deployment. Also, it is possible that individuals previously diagnosed and successfully treated may screen negative on the mental health assessment tools. These study findings should be clinically validated with additional research.
There are no conclusive US military data that document that Pre-DHA mental health screening provides a mental health benefit to service members. Additionally, there are concerns that mental health diagnoses may result in adverse career impact or separation from the military. Regardless, the Pre-DHA is already conducted in all other deploying Department of Defense personnel except shipboard personnel, under the logical premise that addressing mental health issues prior to deployment, even imperfectly, is preferable to not doing so. In addition, current reports documenting mental health in deploying US military are based on Pre-DHA data and are therefore incomplete due to the absence of shipboard deployment data.

US shipboard personnel with mental health conditions need improved screening and treatment in conjunction with career security for those without disqualifying conditions. This survey identified that a significant proportion of shipboard personnel are screen-positive for PTSD and/or MDD, and were not diagnosed with a mental health condition within the past year. If individuals with mental health conditions are identified and linked to care, both the individual and deploying unit will likely benefit. In addition, those with severe mental health issues may be identified prior to experiencing dysfunction in a stressful environment, which may place themselves or shipmates at risk.

Judith Harbertson, PhD, US Military HIV Research Program, Walter Reed Army Institute of Research, Silver Spring, MD, USA; Henry M. Jackson Foundation for the Advancement of Military Medicine, Inc., Bethesda, MD, USA; Department of Defense HIV/AIDS Prevention Program (DHAPP), Naval Health Research Center, San Diego, CA, USA; Braden R. Hale, MD, MPH, Department of Defense HIV/AIDS Prevention Program (DHAPP), Naval Health Research Center, San Diego, CA, USA; University of California, San Diego, La Jolla, CA, USA; Nelson L. Michael, MD, PhD, US Military HIV Research Program, Walter Reed Army Institute of Research, Silver Spring, MD, USA; Paul T. Scott, MD, MPH, US Military HIV Research Program, Walter Reed Army Institute of Research, Silver Spring, MD, USA

Correspondence: Judith Harbertson, PhD, US Military HIV Research Program, Naval Health Research Center, 140 Sylvester Road, San Diego, CA 92106, USA. Email: judith. harbertson.ctr@mail.mil

First received 22 Mar 2016, final revision 16 Aug 2016, accepted 31 Aug 2016

\section{Funding}

This work was supported by a cooperative agreement (W81XWH-07-2-0067) between the Henry M. Jackson Foundation for the Advancement of Military Medicine, Inc, and the US Department of Defense, under Work Unit No. 60546.

\section{Acknowledgements}

The views expressed in this research are those of the authors and do not necessarily reflect the official policy or position of the Department of the Navy, Department of the Army, Department of the Air Force, Department of Veterans Affairs, Department of Defense, or the US Government. Human subjects participated in this study after giving their free and informed consent. This research has been conducted in compliance with all applicable federal regulations governing the protection of human subjects in research.

\section{References}

1 Institute of Medicine. Preventing Psychological Disorders in Service Members and Their Families: An Assessment of Programs. The National Academies Press, 2014

2 Harbertson J, Scott P, Moore J, Wolf M, Morris J, Thrasher S, et al. Sexually transmitted infections and sexual behaviour of deploying shipboard US military personnel: a cross-sectional analysis. Sex Transm Infect 2015; 91 : $581-8$.

3 Weathers FW, Litz BT, Herman DS, Huska JA, Keane TM. The PTSD Checklist (PCL): reliability, validity and diagnostic utility. Paper presented at: 9th Annual Meeting of the International Society for Traumatic Stress Studies; October 1993: San Antonio, TX (available at http://www.istss.org/assessing-trauma/posttraumatic-stress-disorder-checklist.aspx).

4 Radloff LS. The CES-D Scale: a self-report depression scale for research in the general population. Appl Psychol Meas 1977; 1: 385-401. 
5 Hoge CW, Castro CA, Messer SC, McGurk D, Cotting DI, Koffman RL. Combat duty in Iraq and Afghanistan, mental health problems and barriers to care. N Eng/ J Med 2004; 351: 13-22.

6 Riddle JR, Smith TC, Smith B, Corbeil TE, Engel CC, Wells TS, et al. Millennium cohort: the 2001-2003 baseline prevalence of mental disorders in the U.S. military. J Clin Epidemiol 2007; 60: 192-201.

7 Ruggiero KJ, Del Ben K, Scotti JR, Rabalais AE. Psychometric properties of the PTSD checklist-civilian version. J Trauma Stress 2003; 16: 495-502.

8 Terhakopian A, Sinaii N, Engel CC, Schnurr PP, Hoge CW. Estimating population prevalence of posttraumatic stress disorder: an example using the PTSD checklist. J Trauma Stress 2008; 21: 290-300.

9 Warner $\mathrm{CH}$, Appenzeller GN, Parker JR, Warner CM, Hoge CW. Effectiveness of mental health screening and coordination of in-theater care prior to deployment to Iraq: a cohort study. Am J Psychiatry 2011; 168: 378-85.

10 Panagioti M, Gooding PA, Tarrier N. A meta-analysis of the association between posttraumatic stress disorder and suicidality: the role of comorbid depression. Compr Psychiatry 2012; 53: 915-30.

11 Penedo FJ, Dahn JR. Exercise and well-being: a review of mental and physica health benefits associated with physical activity. Curr Opin Psychiatry 2005; 18 189-93.

12 Polusny MA, Erbes CR, Thuras P, Moran A, Lamberty GJ, Collins RC, et al, Mindfulness-based stress reduction for posttraumatic stress disorder among veterans. JAMA 2015; 314: 456-65.

13 Gotnick RA, Chu P, Busschbach JJV, Benson H, Fricchione GL, Hunink MGM. Standardised mindfulness-based interventions in healthcare: an overview of systematic reviews and meta-analyses of RCTS. PLOS One 2015; 10: 1-17.
14 Murphy MJ, Peterson MJ. Sleep disturbances in depression. Sleep Med Clin 2015; 10: $17-23$.

15 Golden RN, Gaynes BN, Ekstrom RD, Hamer RM, Jacobsen FM, Suppes T, et al. The efficacy of light therapy in the treatment of mood disorders: a review and metaanalysis of the evidence. Am J Psychiatry 2005; 162: 656-62.

16 Hoge CW, McGurk D, Thomas JL, Cox AL, Engel CC, Castro CA. Mild traumatic brain injury in U.S. soldiers returning from Iraq. N Engl J Med 2008; 358: 453-63.

17 Marshall BD, Prescott MR, Liberzon I, Tamburrino MB, Calabrese JR, Galea S. Posttraumatic stress disorder, depression, and HIV risk behavior among Ohio Army National Guard Soldiers. J Trauma Stress 2013; 26: 64-70.

18 Dursa EK, Reinhard MJ, Barth SK, Schneiderman Al. Prevalence of a positive screen for PTSD among OEF/OIF and OEF/OIF-era veterans in a large populationbased cohort. J Trauma Stress 2014; 27: 542-9.

19 Armed Forces Health Surveillance Center. Mental disorders and mental health problems, active component, U.S. Armed Forces, 2000-2011. MSMR 2012; 19 : 11-7.

20 Barlas FM, Higgins WB, Pflieger JC, Diecker K. Department of Defense Health Related Behaviours Survey of Active Duty Military Personnel; 2011 (http://www. murray.senate.gov/public/_cache/files/889efd07-2475-40ee-b3b0-508947957a0f/ final-2011-hrb-active-duty-survey-report.pdf). 